\title{
FORUM
}

\section{Amending the Collision Regulations}

\author{
from Peter Clissold
}

I. Introduction. The International Regulations for Preventing Collisions at Sea are of the first importance to the navigator; as Marsden ${ }^{1}$ puts it, they are 'the paramount Rules of Navigation' and it follows that any trouble taken to perfect them is well worth while. They must be comprehensive and clear, simple enough for the sailor yet precise enough for the lawyer. Considering this, the wonder is perhaps that they are as good as they are. Since they are to be discussed at the International Safety of Life at Sea and Load Line Convention this year, the subject of their revision is a topical one and worth the attention of every mariner.

2. History. The story of the Regulations is not without interest. They did not, of course, spring fully fledged into being and they are little more than one hundred years old - a very small fraction of the time that man has been navigating the seas.

Before the Regulations were formulated the practice of seamen had evolved some rules, which were well established by custom and formed part of the general law administered by the Admiralty Court. 1

A rule for ships on opposite tacks is said to have been framed by Lord Howe in 1781 and a rule of 1828 that 'the ship which has the wind at large' keeps out, pointed the first principle of the present rules-that the more manœuvrable craft gives way to the other.

It was when powers of manœuvrability were equal that an empirical rule was required and in $184^{\circ}$ the rule that steamships should pass on the port hand of each other was promulgated by Trinity House and enforced by Admiralty Court. This rule exemplifies the second principle of 'keeping to the right'.

To take proper avoiding action requires knowledge of the approximate heading of the other ship, so it followed that lights that indicated this at night were necessary. On I May I 852 the 'Commissioners for Executing the Office of the Lord High Admiral of the United Kingdom of Great Britain and Ireland, \&c. \&c.', as the Admiralty Notice has it, 2 required and directed that all British steam vessels (whether propelled by paddles or screws) should 'within all sea, gulfs, channels, straits, bays, creeks, roads, roadsteads, harbours, havens, ports or rivers', exhibit a masthead light and side-lights with screens when 'under steam'. All sailing vessels under sail or towed were, on approach, to exhibit a white light and all vessels at anchor a 'common white light'.

The subject was first dealt with by the legislature in 1846 and since that year the law has been added to or altered by four acts of parliament. The only act now in force is the Merchant Shipping Act of 1894 . By that act power is given to her majesty upon the joint recommendation of the Admiralty and the Board of Trade (now, I suppose, the Ministry of Transport) by Order in Council, to make regulations for preventing collisions at sea. 
This has in fact been done in 1910 and most recently in 1954. This last order brought into operation the Rules approved by the International Conference on Safety of Life at Sea, which had been held in London from April to June in 1948 and after 'substantial unanimity' had been reached among the forty countries taking part.

The necessity for rules, or their alteration, has been brought about by changing conditions at sea. At first, no doubt, it was the increasing number of steamships which made international rules, as distinct from generally observed custom, at last essential as they must have been for long desirable. Later, the possibility of encountering seaplanes upon the water had to be allowed for, and now we are faced with the much greater impact of radar upon rules which were devised for vessels in sight of one another.

3. RADAR AND THE Rules. This problem has been studied by a working party drawn from the British, French and German Institutes of Navigation and their report has been published in this Journal (July/Oct., 1959). 'As would be expected in a group of people with widely different backgrounds of experience and responsibility, opinion was not always unanimous' (to quote their report), and they were not able to formulate a rule to cover the situation-new to seamen with the coming of radar-where a vessel sees the echo of another upon her radar screen but cannot tell whether that vessel has 'seen' her or not. Sound advice is contained in the appended 'Guide to the Use of Radar for Preventing Collisions at Sea', but there is no doubt that navigators need a rule also.

4. The general reVision of the Rules. Although it is the effect of radar which makes the revision of the rules imperative, there is a strong case for reviewing them for other reasons as well. In many ways admirable, they nevertheless have come under criticism throughout the years, and it is undeniable that they could be improved in presentation if not in content. Criticisms in our own Journal (there have been 34 direct references to the rules in the 48 issues) have ranged from proposals of fundamental change 3,4 to the indication of imprecisions in wording as seen by a translator of the rules. 5 I have been told that these rules are the product of the finest legal minds, but on reading some of them one can only comment that they do not seem it. The literary style of the rules is remarkably varied. It ranges from the terse clarity, admirably suited to its purpose of, for example, Rule 19, through the leisurely conversational, where 'a bright white light' is 'so constructed as to show an unbroken light over an arc of the horizon' and so on, to the turgid officialese of Rule $1_{3}(b)$.

5. BASIC PRINCIPLES. In considering what revision of the rules is necessary one must not let a preoccupation with the trees prevent observation of the wood. The basic principles of the rules, to which details should conform, are:

(a) that a more easily manœuvred vessel keeps out of the way of a less easily mancuvred vessel;

(b) power-driven vessels of equal manœuvrability keep, in general, to the right;

(c) good seamanship and common-sense are needed in the interpretation of the Rules.

Where lights and shapes are concerned they should indicate:

(a) whether a vessel is easily mancuvred (power-driven vessels), less free to mancuvre (sailing vessels), or unable to manœuvre (hampered vessels); 
(b) if hampered, whether outlying gear is attached to the vessel and, if so, its direction;

(c) when vessels are making way through the water the direction in which they are heading.

It might be a good thing if these principles, implicit though they are, were clearly stated in a preamble to the Rules.

Those who are familiar with the present rules should approach them anew with a fresh mind, as if coming upon them for the first time, asking first the question, 'Is this rule necessary?' and then 'Could it be improved either in content or expression ?' The drafting of a rule is good if it is clear, comprehensive and brief. Simplicity and conciseness are qualities of prime importance for rules which must be memorized and applied perhaps instantly. This, of course, applies particularly to the Steering and Sailing Rules, but even Part B has been consulted upon the bridges of ships in moments of doubt. 6

Revision can consist of what is said and how it is said and it is convenient to consider these aspects separately.

6. Changes and Additions. Most important is a rule to cover the situation of a ship in fog using radar and observing the echo of another vessel who may or may not be using radar. (Even if radar were to be made compulsory equipment, the possibility of break-down must be allowed for.) Though the Guide to the Use of Radar is most helpful it would be of greater value if its advice on manœuvring could be summed up in a concise rule.

The Working Group formulated a set of conditions to be fulfilled before any system of regulating manœuvre when radar was the only source of information could be accepted. These conditions, of which the first is that the master should be left complete discretion as to the type and direction of manœuvre, are laid out in the Group's Report.

I do not see how any rule can leave the master 'complete discretion' except as qualified by Rule 27, but it will be agreed that the least possible restriction should be imposed. It will also be agreed that the manœuvre required should correspond as closely as may be with clear-weather practice. In a simple crossing situation where one ship (A) has the other (B) fine on her starboard bow, $\AA$ would (in fine weather) alter course to starboard, bringing ship B fine on her own port bow, and there is certainly a tendency for this manœuvre to be carried out in fog. (In 18 radar plotting exercises carried out by students left to act as they thought best, all but one altered course to starboard; the one alteration to port led to a close-quarter situation.). What should B's action be in fog ? She is not bound 'to keep her course and speed'. A may not have detected her presence; if she has not, she will take no avoiding action, and it would be imprudent for $B$ to stand on until in sight of $A$. If $A$ has detected $B, A$ will probably alter course to starboard. Probably B's best action would be to reduce speed drastically and wait until A has either drawn ahead or has altered course to pass under B's stern. But whatever B does she should not alter course to port because this would counteract A's natural avoiding action (if any). This reasoning applies to every case where A's response will be to alter course to starboard, i.e. from an echo bearing from right ahead of $A$ to about on her starboard beam. I believe the solution could be summed up in a rule.

Next in importance is Rule 9, which at present seems unnecessarily complicated and, in places, far from clear, though much less wordy than the i 910 rule. 
Fishermen are not notably punctilious in carrying out the requirements of the present rules and a simpler and more easily comprehended rule should help them to a closer observance.

There are several anomalies. One cannot tell from a trawler's lights whether she is coming directly towards you or going away: the triangle of lights displayed by a drift net vessel does not indicate the direction of her lengthy nets: while a fisherman is likely to have as much difficulty in interpreting the intricacies of paragraph (h) as he will in disentangling the gear described in that paragraph. Opinions among fishermen appear to differ very much and their main causes of complaint are the confusing variety of unofficial signals used by different nationalities. This may be because the international ones are inadequate. The point of view expressed here is that of the approaching navigator. He wants to know: whether the other vessel is fishing, for if so he must avoid it; the direction and, as far as possible, the extent of the gear, for he must avoid that also; if the fishing vessel is moving through the water, the direction in which she is heading. A fisherman may want to know more and it has been suggested that there should be signals for trawlers shooting and hauling their trawls. The following proposals make Rule 9 simpler to understand and follow and are possibly adequate:

In paragraph (c) (vessels with gear extending not more than 500 feet), the second white light, and a second basket by day, to be made optional. Unless the gear extends a considerable distance from the boat there is no point in indicating its direction. The fisherman himself should be the best judge of whether it is desirable to show this or not.

(d) (Vessels with gear extending more than 500 feet), add to the three white lights in a vertical triangle in the fore and aft line another white light in the direction of the gear. This agrees with the M.O.T. Notice which states that 'an all-round white working light is commonly carried in the forepart of the vessel when she is lying to her nets', the triangle being carried aft.

(d) (i) To the approaching vessel a power-driven vessel trawling is simply one which 'is not under command and cannot therefore get out of the way' and there seems no reason why, as such, she should not carry the two red not-undercommand lights plus her side lights and stern light.

(g) Is it desirable to complicate fishing signals by the addition of anchor lights? The approaching ship will know that the vessel is fishing, in which direction her gear extends, and that she is not making way through the water. Additional lights will tend to confuse these and add little important information.

(h) I understand it to be the practice for fishing vessels in this unenviable position to keep the triangle of white lights on in spite of what the rule says, and since the gear still extends to seaward and must be avoided by approaching vessels this seems reasonable enough. This paragraph could be omitted, but it would be useful if any vessel fishing could sound, at any time, her fog fishing signal to warn an approaching vessel off her gear, but certainly not ' $D$ ' as prescribed in this paragraph.

There is one rule in which the fundamental principle that the more easily manœuvred vessel keeps out of the way of the less easily manœurred vessel has come to be violated. Rule 17 (for sailing vessels) was, of course, originally intended principally for square-rigged vessels, and a square-rigged vessel running free could alter course a considerable amount without trouble; whereas to tack ship might well require all hands on deck. So it was sensible to rule that vessels 
running free should give way to those close-hauled. Today cases must be rare indeed where two square-rigged vessels are approaching each other so as to involve risk of collision and the logical reason for the rule has disappeared. A fore-and-aft rigged vessel running free, particularly if she has a spinnaker set, may well find it difficult to alter course, though if she was turning to windward she would go about with little trouble. Changed conditions at sea have thus rendered the once good rule no longer desirable. There is, too, a grave weakness in the present rule. To apply it, you must know how the other vessel has the wind, and there are cases, at night, in which it is not certain whether the approaching vessel is close-hauled or free. Suppose you are upon the port tack and see a red light upon your lee bow. That vessel may be close-hauled on the starboard tack-in which case you must give way-or she may be just free with the wind on the starboard side-in which case you must stand on. Again, if you have the wind free on the starboard quarter and see a red light on the starboard bow, it may belong to a vessel close-hauled or running free with the wind on the port side.

There is now little reason why a sailing vessel when meeting another should not follow the same rules as a power-driven vessel. It should not be necessary for a sailor to memorize and apply one set of rules when sailing and another set when under engines. There is a large number of amateur sailors to be met today and both for their safety and that of others one set of rules instead of two would be a distinct improvement.

Alternatively, a simplification of the present rule has been proposed by the Royal Yachting Association in which all vessels with the wind on the port side (irrespective of whether they are close-hauled or not) keep clear of vessels with the wind on the starboard side. This rule has already been adopted for racing by some 25 countries.

7. The wording. The number of additions to the rules which will inevitably be proposed at the Conference make it more desirable than ever that the rules should be kept as concise as possible. There are several ways in which the drafting can be improved: (I) the use of one word to express one meaning, e.g. 'carry' instead of 'show', 'exhibit', 'display', \&c. used almost indifferently; (2) the inclusion of a seaplane in the definition of a vessel in all rules, and not only in Rules 19, 20, would avoid about a dozen special references to seaplanes, 'when it is not possible for seaplanes to comply fully with the provisions of the rules specifying the carrying of lights and shapes these provisions shall be followed as closely as circumstances permit', is already stated in Rule I ; (3) the concentration, where possible, as in Rule 18 , of the rule in the first paragraph and the relegation of subsidiary or amplifying matter to notes, as in the proposed new radar rule; (4) the extension of definitions in Part A. Just as 'all seas, gulfs, channels, straits, \&c.' has been combined in 'the high seas and all waters connected therewith', we could with advantage define 'fog' to include 'fog, mist, falling snow, \&c.' Other definitions listed in Part A could be 'in sight of' (i.e. in direct visual contact), 'trawling' and 'trolling' (is this word really necessary ?), 'steaming (or masthead) light, side lights and stern light', and 'overtaking vessel'. Also, and not hitherto used in the rules, the concept of a 'hampered vessel', i.e. a vessel which cannot get out of the way of an approaching vessel because, not under command, laying or picking up a submarine cable or navigation mark, engaged in underwater operations, or surveying, trawling, or a vessel towed if only manœuvring, or being manœuvred, with difficulty. The adoption 
of this term enables a great simplification of lights and shapes required to be carried, and of giving way procedure.

8. ACKNOWLEDGMENTS AND sources. No originality is claimed for the changes proposed, for no doubt the best ones have occurred to many other people at various times. I am indebted to Captain A. Simpson of Aberdeen and Captain I. Allison of Hull, who were good enough to discuss Rule 9 with members of their staff and fishermen and to let me know the result, and to some of my friends and colleagues at the School of Navigation, Warsash, for their friendly and uninhibited advice.

\section{REFER ENCES}

1 Marsden, Collisions at Sea, gth edition, Ed. A. D. Gibb.

2 Marryat, F. and Richardson, G. B. The Universal Code of Signals, i 850.

3 Gauw, Rear Admiral J. (1 955 ). Radar and collision at sea. This Journal, 8, 178.

4 Fendig, Lt. Cmdr. R. (1958). A frame of reference at sea. This Journal, i 1, 407.

5 Azad, A. (1959). The Collision Regulations through a translator's eyes. This Journal, 12, 201 .

6 Marsden, op. cit., the case of H.M.S. Truculent.

\section{from Lt. Cmdr. N. L. Fendig, u.s.c.G.}

Captain Brett Hilder in the July/October issue of this Journal stated that the use of true direction as a frame of reference at sea would lead to confusion. To prove his point, he used the analogy of vehicle traffic on highways.

In dealing with ships at sea, we are attempting to avoid collisions between two or more objects on a plane surface, each having a $360^{\circ}$ freedom of horizontal movement in most cases. The surface of the sea gives no reference points. Vehicular traffic, on the other hand, is limited to the highway and uses the road itself as a reference, keeping to the right in the United States and to the left in Britain. In the United States, many highways have a painted white centreline. In most countries, roads entering or crossing main highways have stop signs or control lights. These artefacts are missing on the ocean. Where similar frames of reference are available, as in narrow channels, keeping to the right may be satisfactory as a rule for avoiding marine collisions.

A gyro-compass repeater card, with one semi-circle tinted red and the remainder white would provide an objective frame of reference. Vessels bearing red would have to be avoided, just as radio operators must cease transmitting and listen when the minute hands of their clocks are in the red sectors.

The example provided by automobile traffic in America might be employed by ships broken down or with restricted manœuvrability. Good practice in such cases is to display a flashing red light.

Though Captain Hilder deserves credit for endeavouring to bring out an essential basis for the rules, an elaborate caste system of relative manouvrabilities could be viewed as a reductio ad absurdum for the present pattern. Vessels falling within various categories of limited capabilities could well be lumped together for simplicity and required to stop or go slow when encountering traffic. The radar-equipped fast vessel might then be free to gain an economic advantage from her superior equipment rather than merely increased legal liabilities.

If we are eventually to have automatic anti-collision devices for use at sea, objective rules would be useful. Altimeters on planes provide an instrumental 
means of increasing safety during periods when blind flying is necessary, and regulations relate altitudes to courses in order to take advantage of this possibility. The construction of increased numbers of submarines, as well as other vessels of novel configuration, will eventually force a basic reconsideration of the marine Rules of the Road, which appear to have been drawn initially for vessels using a common means of propulsion and a common frame of reference, the wind.

\section{Captain Brett Hilder comments:}

Commander Fendig is to be congratulated on his bold approach to the subject, for that is just what has been lost, along with simplicity, in the details of the present Rules. He says that the sea has no frame of reference, but each ship has a frame, which makes it easier and quicker to say that a vessel sighted is on the starboard bow, than to say whether she bears a little west of north. The basic Steering Rules, which might well have been in use before the magnetic compass, suit ships in mid-ocean or in a narrow fairway or river, and I cannot see that they need improvement. Even when a machine for avoiding collisions can be built into automatic gyro-pilots, the frame of reference of the ship will remain the principal argument in the problem to be solved.

Commander Fendig's suggestion for a flashing red light for ships in trouble is to be commended as the sort of thing needed, and I should like to draw attention to a device called a 'Trafficator' which is to be proposed to the coming meeting of the International Safety of Life at Sea Convention in London. This device is a signal mast above a ship's bridge, and controlled by switches on the bridge, to give flashing lights to indicate alterations of course. These are in addition to the usual sound signals, and the proposal is for a flashing green light to show a turn to starboard, a flashing red light for a turn to port, and a flashing blue light to mean movement astern. To these might be added a flashing white or amber light to mean 'I am standing on, what are you going to do about it?'

The 'Trafficator' is being marketed by a firm at Rotterdam and was described in Reed's Marine Equipment News for March 1959, with a photograph of one fitted to a ship. I don't suppose that the lights used are powerful enough to be seen by day, so we may still need some visible signal to supplement the present sound signals.

My previous suggestion in this Forum that ships of reduced manœuvrability should be classed by their ability at the time, and not by their occupation or trade, was intended to cater for the present number of different classes mentioned in the rules. Most of these vessels are 'unable to manœuvre in accordance with the Rules', or unable to move freely. They may be chasers fast to whales, ships fast in pack ice, trawlers fast to the ground, survey ships dragging wires, or ships with divers down. Commander Fendig has suggested that such vessels be classed together and further immobilized to allow free and unimpeded ships to shoot through like Coast Guard cutters. This solution seems unrealistic as well as uncharitable. The moral intended appears to be: 'If you can't get out of my way, then keep out of my way!'

$$
\text { from W. B. R. Taylor }
$$

THE proposed changes in the Collision Regulations as drawn up by the Working Group (of the British and French Institutes of Navigation and the Ausschuss für 
Funkortung) and also the proposed guides to radar practice, as published in the July/October 1959 Journal, make very interesting reading and deserve serious study by all interested parties.

The guides to radar practice I consider admirable, and I will leave others to comment on these if they so desire. I wish, however, to offer a few comments on the proposed changes in the Collision Regulations.

It is a fact that each time the Collision Regulations have been revised they have taken on a longer and more complex form than before. The present proposals of the Working Group are no exception, though they should be congratulated on the additions being not so numerous nor as ponderous as they might have been. If the Collision Regulations are added to much more in this fashion, I fear that the day is not far hence when every ship will have to carry a lawyer on the bridge to appraise and interpret each situation on its merits.

It was rather interesting that in the same issue of the Journal should appear Captain Brett Hilder's comments on the Collision Regulations. In the main I should like to endorse heartily his ideas of a drastic change in the present rules, giving birth (we hope) to a streamlined set of rules, which are simple in interpretation and application. The idea of classifying ships by their degree of manouvrability instead of by their occupation has more to commend it from the point of view of collision avoidance. Of course there is one class of vessel which will have to retain a distinctive signal to indicate its occupation, namely the pilot vessel.

When rules get too ponderous and complicated it always allows loopholes for ambiguity. As an illustration of this statement, let us consider the following:

(a) Rule 2, iii, concerning the positioning of the foreward masthead light states that 'the light need not be placed at a greater height above the hull than 40 feet' and goes on to say that the light 'shall be so placed as to be clear of and above all other lights and obstructing superstructures'. How can large vessels comply with both these requirements? Surely it would be easier to state a minimum height (say $20 \mathrm{ft}$.) and the maximum to be simply above all other lights and superstructures, leaving out all the rest of the verbose details.

(b) It is obvious from the present Rule 8 that sailing pilot vessels do not carry stern lights, but it is rather in doubt whether power-driven pilot vessels come under the exemption or not.

(c) Rule i 5 leaves doubts about the fog signal for a vessel engaged in fishing with outlying gear whilst at anchor. Is such a vessel covered by sub-section (c) iv or by sub-section (c) ix?

(d) Rule 18 is a classic example of unnecessary repetition; sub-section (a) could very well end with the phrase "on their respective courses, pass clear of each other', without any fear of ambiguity.

The seaman is a naturally conservative individual and raises his hands in horror at sudden and drastic changes, and I can imagine some saying, 'What sort of confusion will result if such drastic changes are made in the Collision Regulations?' However I am sure that each watch-keeping officer has enough intelligence to adapt himself to the new situation, should it arise, and afterwards probably wonder why the 'old' archaic rules held force for so long. So far as I know all seamen consider the present regulations ambiguous in some form or another. Commander Clissold's list of ambiguities in the October 1958 edition of the Journal could quite easily be disposed of in a set of rules drawn up on the principle of 'degree of manœuvrability'. 
This seems to be a very appropriate time to adopt a complete change in outlook, which will lead to simplicity, and avoid ambiguous situations; the reputation of the cloth is at stake at present with so many adverse criticisms in the national press about 'radar-assisted collisions', and letters to the editor of one national newspaper about the intelligent use of radar at sea.

If completely new rules should ever be drawn up do please let it be clear which code applies in good visibility and which in restricted visibility. Also it would doubtless be necessary for a vessel equipped with radar to be allowed a higher degree of manœuvrability than her sister without this aid.

\section{'The Effective Use of Airspace'}

\section{from Wing Commander A. W. Southall}

I. INTroduction. It is almost two years since Wing Commander Dickie's survey (I 1, 259) emphasized the importance of improving methods of control so as to allow more movements in a given volume of airspace. Since then, much effort in many countries has been devoted to the problem. The magnitude of these difficulties is not surprising when it is recalled that, in addition to the professional difficulties of flying, navigation and control, various sections of industry are involved, and international agreement must be obtained. At every turn there are political and commercial problems which cannot be ignored by those responsible for initiating action to solve a very difficult practical problem. This note is written in an attempt to examine once again the various possibilities for improving airspace utilization, with the object of discovering some pattern which will lead to progress.

2. Navigation. It has been stated that at all times both the controller and the pilot must know the absolute ground position of the aircraft, but it is by no means clear that this really is a requirement. It could well be sufficient to maintain the position of the aircraft relative to the traffic pattern, for this would satisfy the pilot's aim which is to travel in accordance with his flight plan, and also the controller's aim which is to ensure safety while making best use of the available airspace. If it is indeed sufficient to maintain position in relation to the traffic pattern, then we have the opportunity to view the navigation problem from a standpoint consistent with the control problem.

3. Tracking. Given accurate tracking in the air, airspace limitations will become a much smaller problem without extra effort in the control centre. Let us consider the tracking device from the point of view of keeping the aircraft in position in the traffic pattern. First and foremost the device must keep going. Black boxes which are prone to failure are worse than useless, especially if bad weather makes their failure more likely. It has always been good navigation policy to cross-check the navigation, and for many years yet, some reserve navigation method will be required. If the main navigation device is not weather sensitive, then it may be possible for the ground radar to provide the reserve against occasional failure, and this would seem to be the most economic proposition. These general considerations lead to the question of presentation of tracking information on the overcrowded flight deck. It may well be found sufficient for the required track to be preset, and for off-track indications, and possibly 